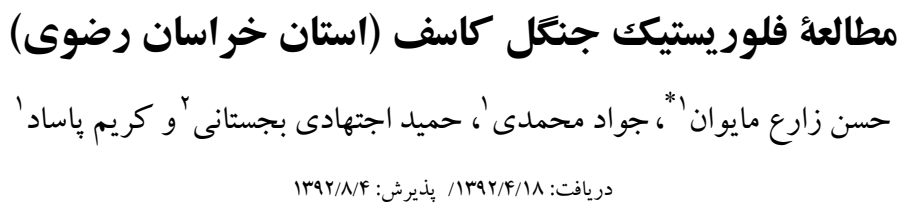

' انشكدة علوم زيستى، دانشخاه تربيت مدرس تهران، تهران

'دانشكدة علوم بايه، دانشگاه فردوسى مشهد ، مشهد

zare897@yahoo.com :مسئول مكاتبات*

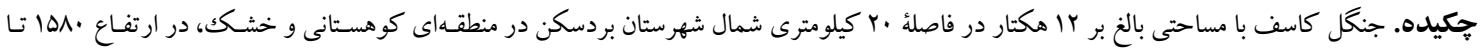

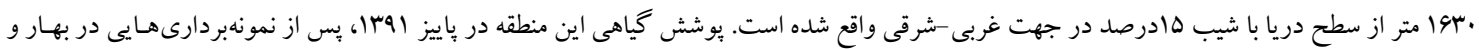

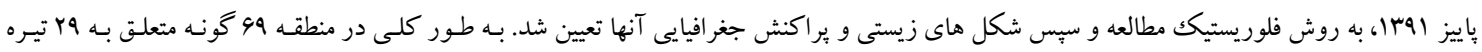

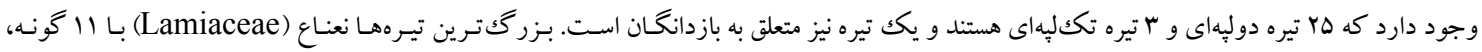

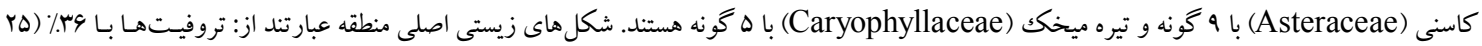

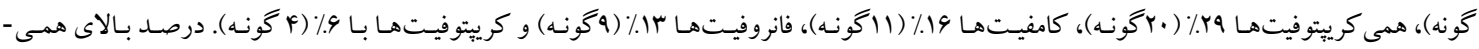

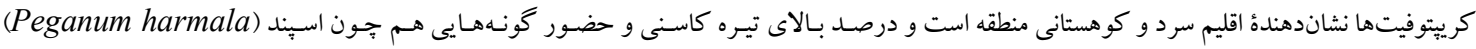

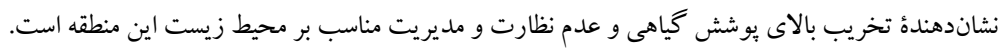
وازههاى كليدى. فلور، يراكنش جغر افيايى، شكل زيستى

\title{
Floristic study of Kasf forest (Khorasan Razavi Province)
}

\author{
Hassan Zare- Maivan ${ }^{* 1}$, Javad Mohammadi ${ }^{1}$, Hamid Ejtehadi- Bajestani ${ }^{2}$ and Karim Pasad $^{1}$ \\ Received 09.07.2013/ Accepted 26.10.2013
}

${ }^{1}$ School of Biological Sciences, Tarbiat Modarres University, Tehran, Iran

${ }^{2}$ Faculty of Sciences, Ferdowsi University of Mashhad, Mashhad, Iran

* Correspondent author: zare897@yahoo.com

\begin{abstract}
Kasf forest, with an area of over 12 ha, running in the east-west direction and located at a distance of 20 kilometers in the north of the city of Bardaskan in a mountainous arid region. The minimum and maximum temperature of the area ranges between $-10^{\circ} \mathrm{C}$ and $+45^{\circ} \mathrm{C}$. The average annual precipitation of the region is 155 $\mathrm{mm}$. The altitude of the forest is about $1600 \mathrm{~m}$ above sea level with a $15 \%$ slope. The vegetation of this forest was studied using floristic methods 2 years after a devastative fire and life forms and geographical distributions of plant species were determined. Sixty nine plant species belonged to 29 families (25 Dicots, 3 monocots and one gymnosperm). The largest families were the Lamiaceae with 11, Asteraceae with 9 and Caryophyllaceae with 5 species. The percentages of life forms were determined as follows: Therophytes with $36 \%$ ( 25 species), Hemicryptophytes with 29\% (20 species), Chamaephytes with 16\% (11 species), Phanerophytes with 13\% (9 species) and Cryptophytes with 6\% (4 species) of total investigated species. The high percentage of Hemicryptophytes indicated the dominance of cold mountainous climate and the presence of Asteraceae species such as harmala (Peganum harmala) showed that a severe disturbance had taken place in the region, which indicated a poor ecological administration in the studied region.
\end{abstract}

Keywords. flora, geographical distribution, life form 
كثــورهاى داراى بوشـش جنگلسى زيــر ده درصــ تلقسى

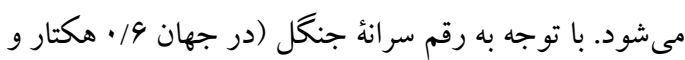

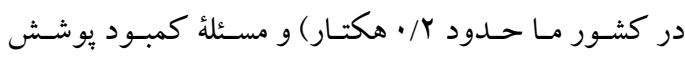

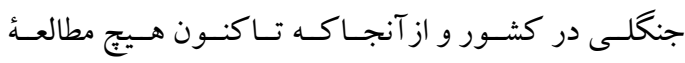

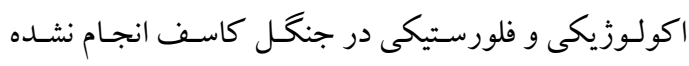

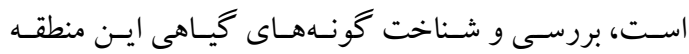
ضرورى به نظر مىرســـ بنابراين هـدف ايـن تحقيق تعيين

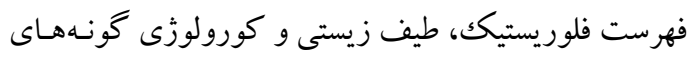
كياهى منطقه تحت بررسى است.

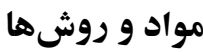

\section{ويزگكىهاى منطقة بررسىشده}

شهر ستان بردسكن در حاشيئ شـمالى كوير نمكك، بين ه9 درجه و Fا دقيقه تا مها درجه و ها دقيقه طول و Fا درجسه و

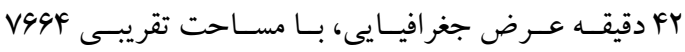

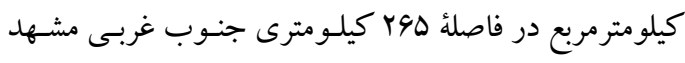

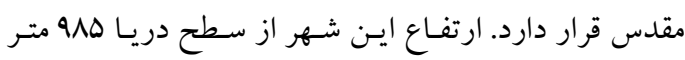

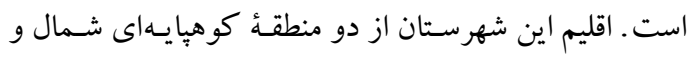
جلكهاى جنوب شامل بيابان، نمككزار و شنزارهـاى حاشيئ كوير نمك شكل خرفته است.

روستاى كاسف يكى از روستاهـاى منطقـة كوهِيايـاى

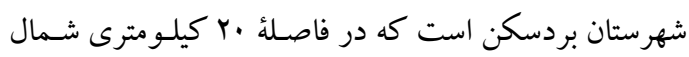

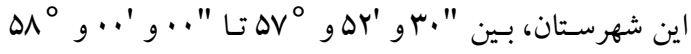

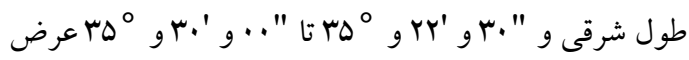

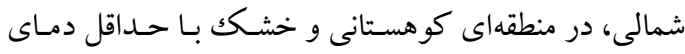

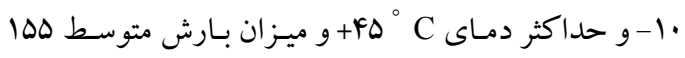

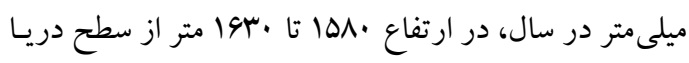

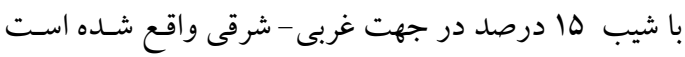

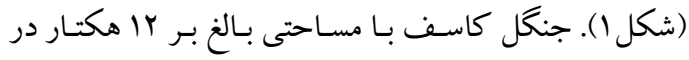

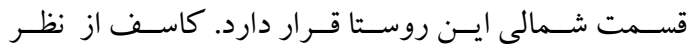

به طور كلى، يوشـش كياهى هـر منطقه يكى از مهـم ترين يديدهاى نمود جهره و سيماى طبيعت و بهترين راهنماى ليهاى

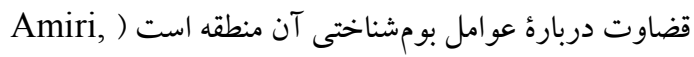
2010). فلور هر منطقه نتيجه واكنش هاى جامعـهٔ زيستى در

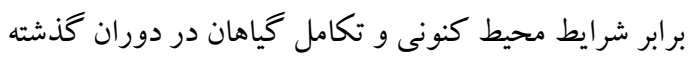
است. با توجه به نقش شناسايى گياهان و اهميت انكارنايذذير

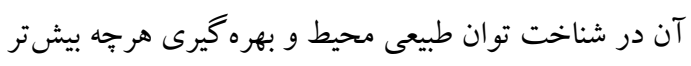

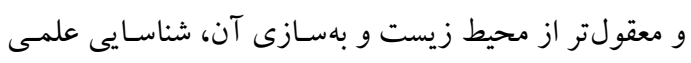

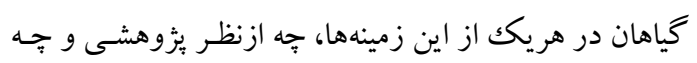

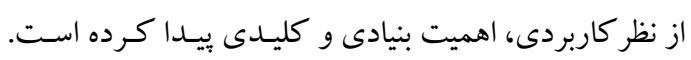

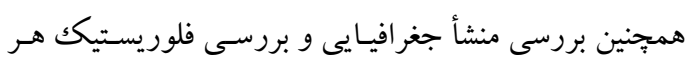

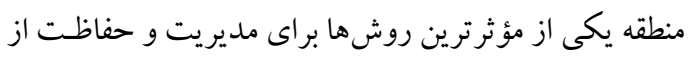

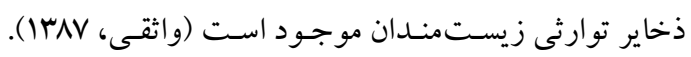

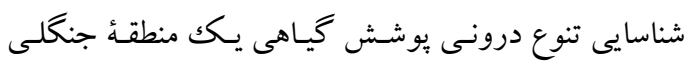

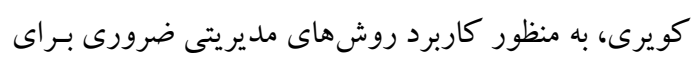

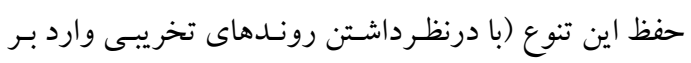

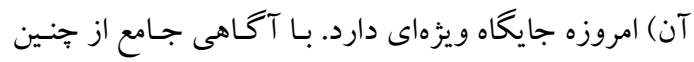

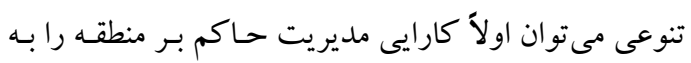

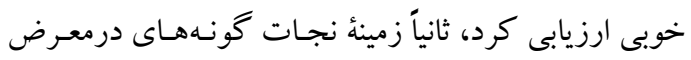

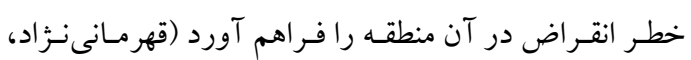

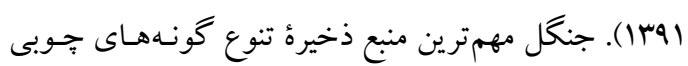

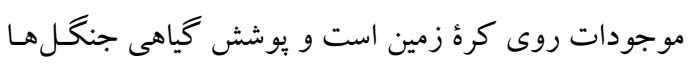

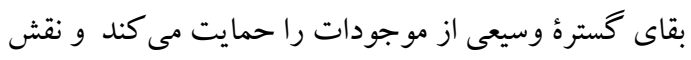
مهمى در كاهش و كنترل فقر در مناطق خشك و جلو گيرى

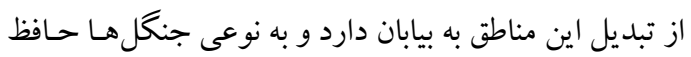
بقاو كار آيى مناطق خشك هستند. ايران ب/ آ ميليون هكتار عرصة جنكلى دارد كه جيزى در حدود V/9 درصد مساحت

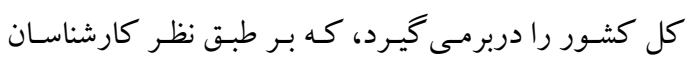

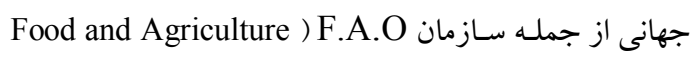
(Organization of the United Nations 


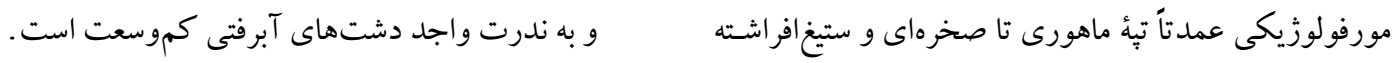

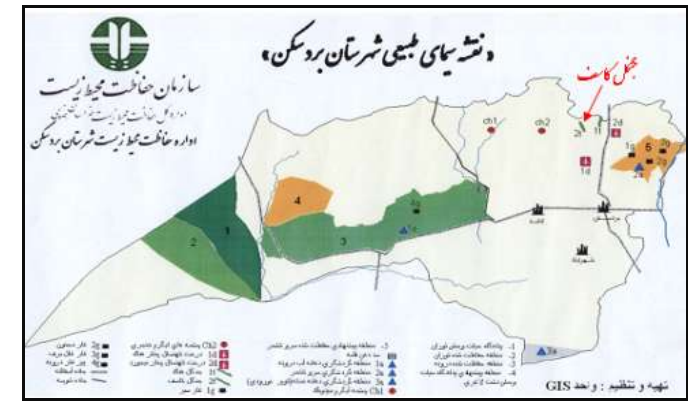

شكل ا- سيماى طبيعى شهرستان بردسكن وموقعيت جغرافيايى جنكل كاسف.

Fig. 1. Bardaskan city natural landscape and geographical location of forest Kasf.

تعيين شكلزيستى بهوسيلة سيستم رانكاير انجام كرفـت.

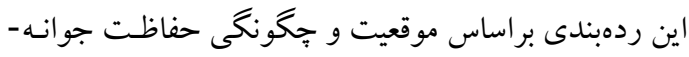

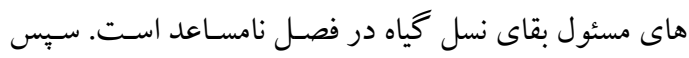

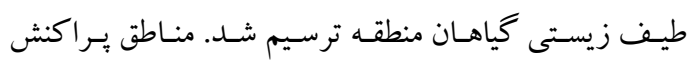

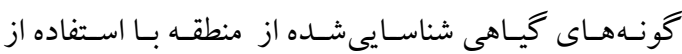
كتابهاى فلور و منابع مذكور تعيين شدائ.

نتايج

نوع اقليم منطقهـ براسـاس ضريب خشكى دومـارتن (I/ه9)

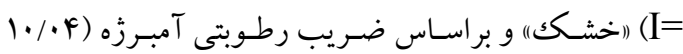

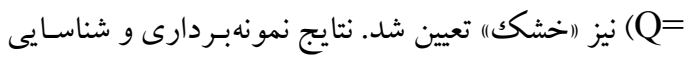

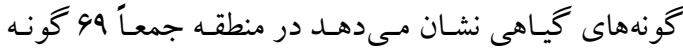

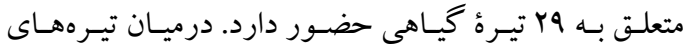

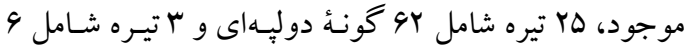

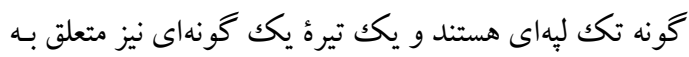

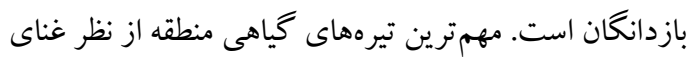

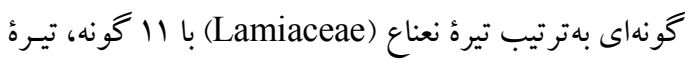

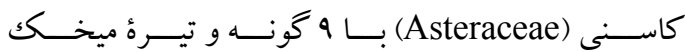

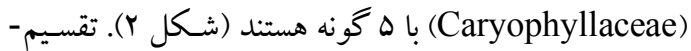

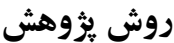

براى تعيين فلور منطقه، ابتدا اطلاعـات لازم مانــد آمارهـاى

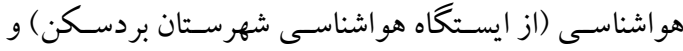

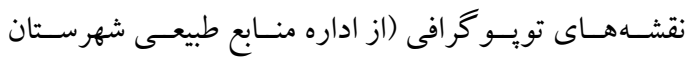

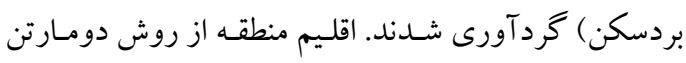

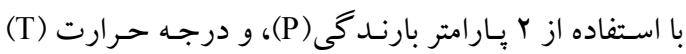

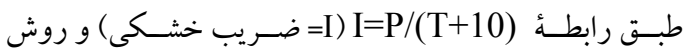
آمبرزه با استفاده از يُرامترهاى متوسط بارند گى سـالانه(P)، متوسط حداكثرهاى دما در گرمترين مـاه سـال (برحسبـ

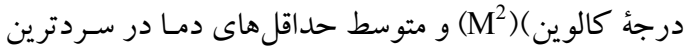

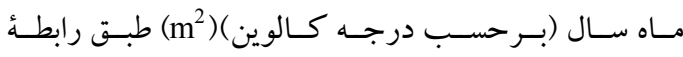

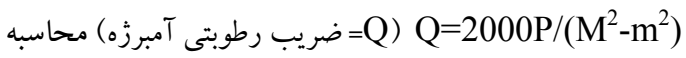

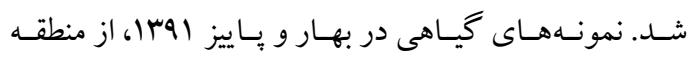

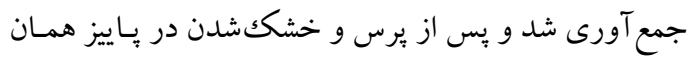

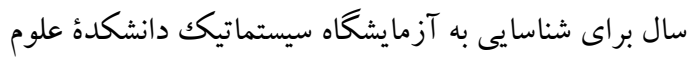

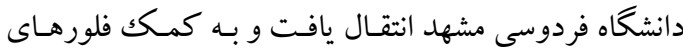

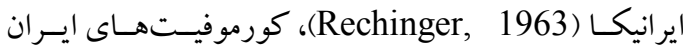
Ghahreman, ) فلور رنغى ايران (Ghahreman, 2004) 2006) و فلور ايران (اسدى، ع عז1) شناسايى شد. 


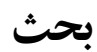

با توجه به موقعيت قرارگيرى ايـن جنخل، كـه درون درهاى در حدفاصل ب كوهو و در اطراف آبراهـاى كـه از اين دره

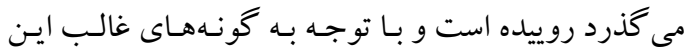

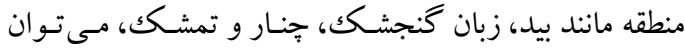
كفت اين جنگل ازنوع جنكلهـاى كويرى (Oasis) است كه در منطقهاى با آب و هواى خشك و نسبتاً سرد به وجود جنو

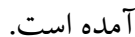

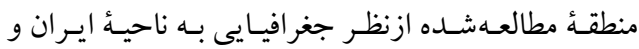

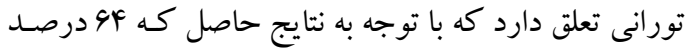

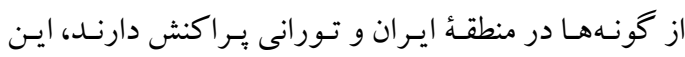
مطلب تأييد مىشود. طبق نظر Archibold فراوانى كياهـان

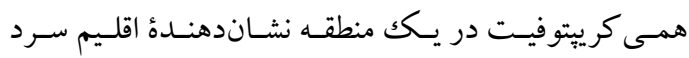
كوهستانى آن است (Archibold, 1995)، كه نتايج اين بررسى غلبه همى كرييتوفيـتهـاو تروفيـتهـا را در منطقـهـ نشان مى دهد. دليل اينكه تروفيتهـا بيشترين درصـد را بين فرين

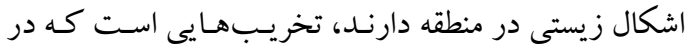

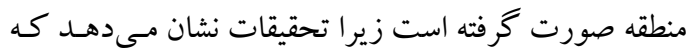

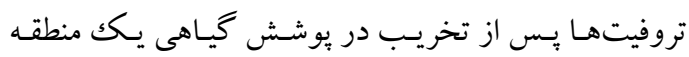

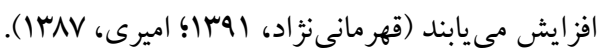
با توجه بـهـ گرم وخشكك بودن فصـل تابستان وفقــان بارش نزولات آسمانى در اين فصل، سـاز كارى كامفيتهـا با جنين شرايط اقليمى باعث شده كه آنها به منزلة مقاومترين

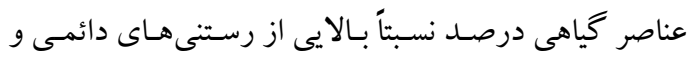
بايدار منطقه را به خود اختصاص دهند و درمقابل، تروفيت-

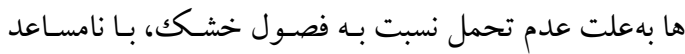

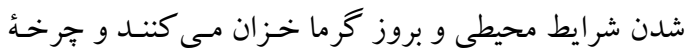

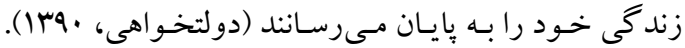
يكى از دلايـل حفظ ذخيرة رطوبـت خـاكن، غالب بـودن

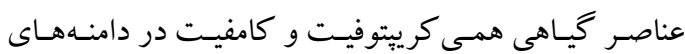

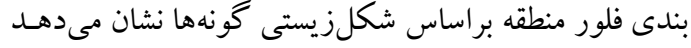

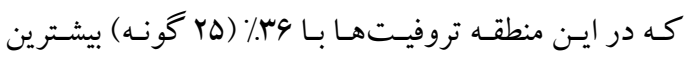

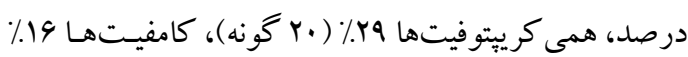

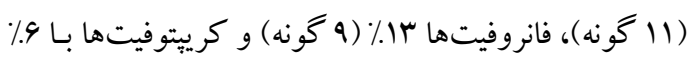

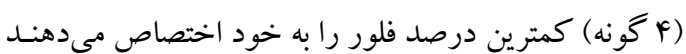

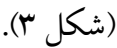

$$
\text { مِراكنش جغرافيايى گياهان منطقه بهاين صورت است: }
$$

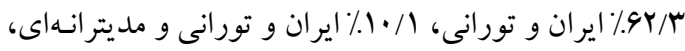

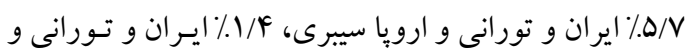

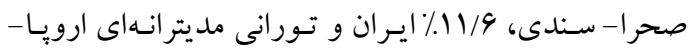

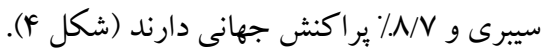
كونههاى غالب در اشكوب علفى عبارت اند از:

Scandix pectin-veneris, Alyssum linifolium, Bromus tectorum, Nepeta bracteata, Lactuca glauciifolia, Chenopodium botrys, Ziziphora tenuior

$$
\text { و گونهاى غالب در اشكوب درختى عبارت اند از: }
$$

Platanus orientalis, Salix alba, Fraxinus rotundifolia, Rubus sanctus, Populous alba

$$
\text { كونههاى بومزاد منطقه عبارت اند از: }
$$

Dianthus orientalis subsp. aucheri, Pteropyrum stenocalyx

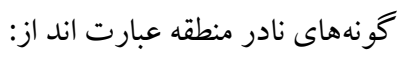

Astragalus schahrudensis, Cleome khorassanica, Salvia leriifolia

كونهاى جهانزى منطقه عبارت اند از:

Bromus tectorum, Descurainia sophia, Cirsium arvense, Mentha longifolia, Solanum nigrum, Juncus articulates 


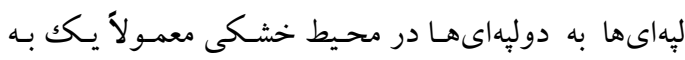

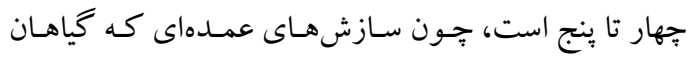
دوليهاى درجهت زيست در مناطق خشكك بيـدا كردهانـد،

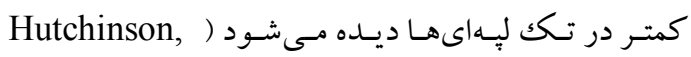

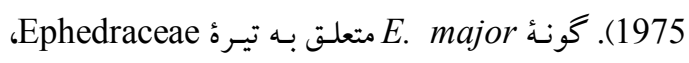

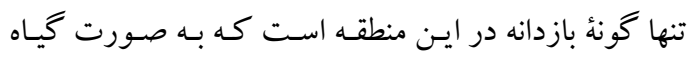

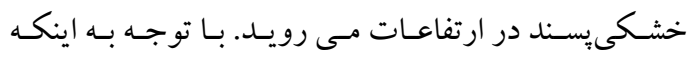

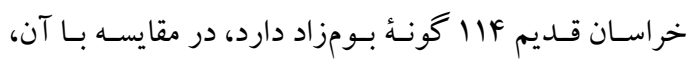

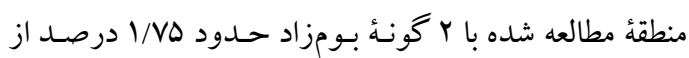

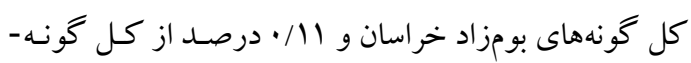

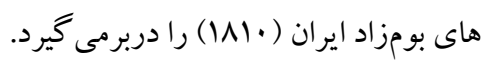

شيبدار ارتفاعات كوهستانى است و تنوع اشكال زيستى كامفيتها نقش بسيار تعيين كنندهاى در تثبيت خاكك بهويـزه

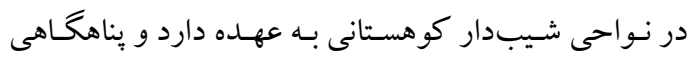
براى استقرار عناصر زيستى همجون تروفيتها را فراهم مى -

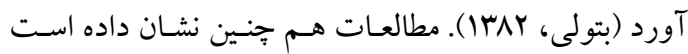

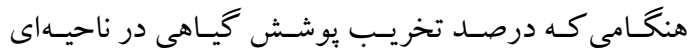

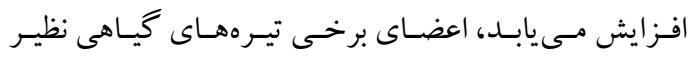
Asteraceae حضور بيشترى در فلور منطقهـ ييدا مسى كنتـد

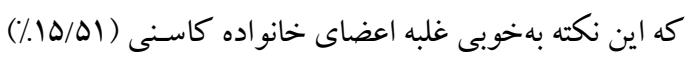
را در منطقه سوخته توجيـه مس كنــد (قهرمانىنزاد، الوبا؛

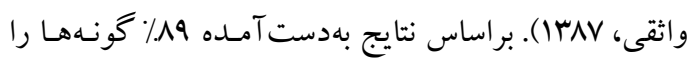

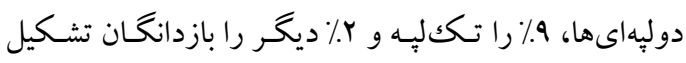
دادهاند. طبق نظر Hutchinson، به طور كلى نسبت تكك- دكا

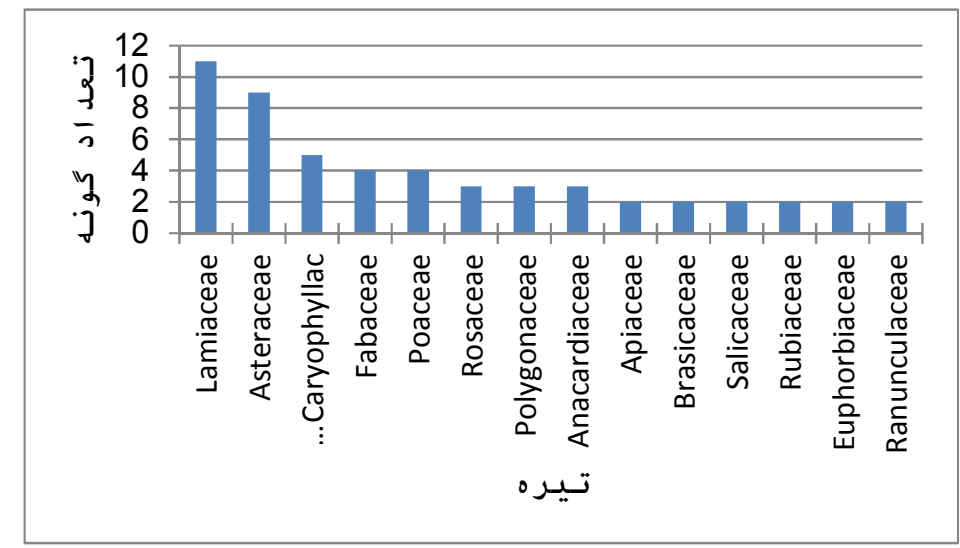

شكل Y- ت تيرههاى داراى بيشترين تعداد گونه در منطقه.

Fig. 2. The families with the highest number of species in the study area. 


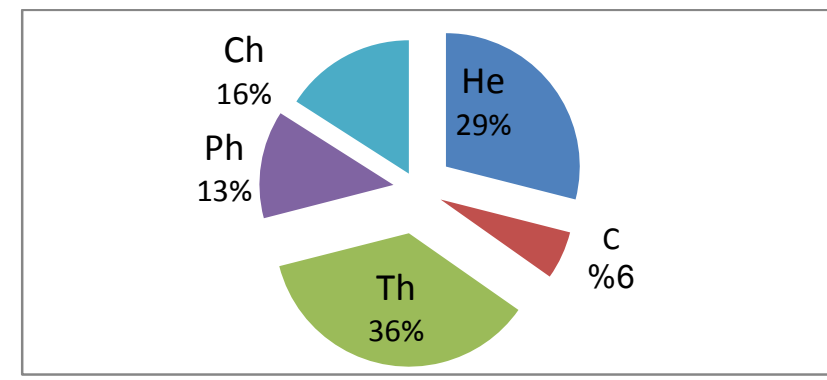

$$
\begin{aligned}
& \text { شكل r- طيف شكل هاى زيستى در تر كيب فلورستيك منطقه. }
\end{aligned}
$$

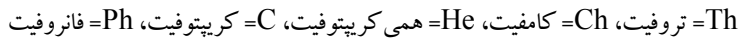

Fig. 3. Spectrum of life forms in the floristic composition of the study area.

$\mathrm{Th}=$ Therophytes, $\mathrm{Ch}=$ Chamephytes, $\mathrm{He}=$ Hemicryptophytes, $\mathrm{C}=$ Cryptophytes, $\mathrm{Ph}=\mathrm{Phanerophytes}$

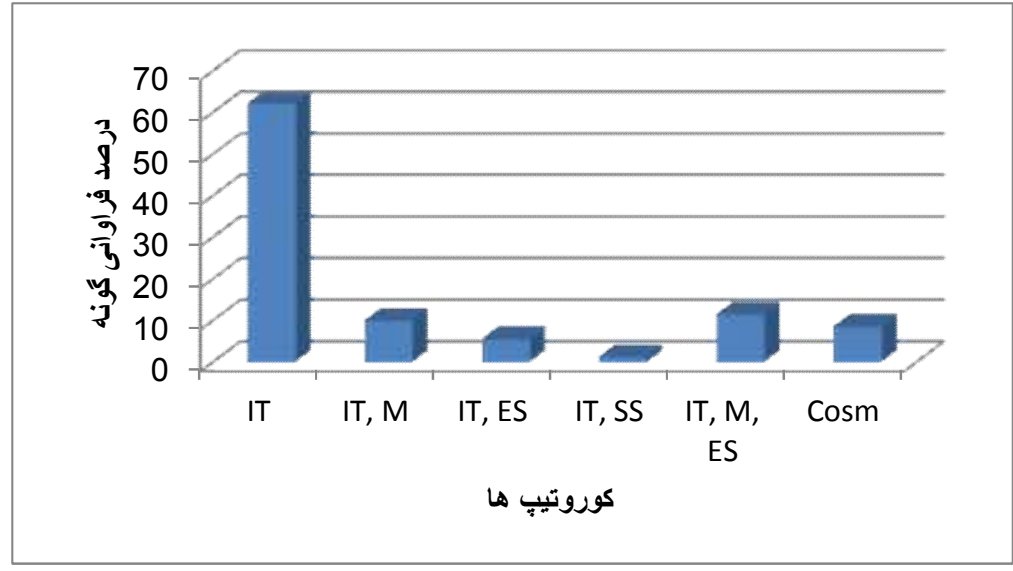

$$
\text { شكل ץ- فراوانى يراكنش جغر افيايى گياهان منطقه. }
$$

IT

Fig. 4. Frequency of geographical distribution of the area plants.

$$
\text { جدول ا- فهرست نام علمى، شكل زيستى و كوروتيب گونهاى گياهى منطقه. }
$$

\begin{tabular}{|c|c|c|c|c|}
\hline كوروتيبٍ ** & شكلز شيستى * & 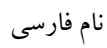 & 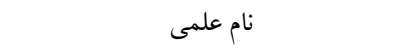 & رديف \\
\hline \multicolumn{5}{|c|}{ Anacardiaceae } \\
\hline IT & $\mathrm{Ph}$ & بنه & Pistacia atlantica Desf. & 1 \\
\hline IT & $\mathrm{He}$ & زول & Eryngium billardieri F.Delaroche & r \\
\hline
\end{tabular}

Table 1. List of scientific names and life forms of plant species of the study area. 


\begin{tabular}{|c|c|c|c|c|}
\hline IT & $\mathrm{He}$ & كما & Ferula ovina (Boiss.) Boiss. & $r$ \\
\hline \multicolumn{5}{|c|}{ Apiaceae } \\
\hline IT & $\mathrm{He}$ & كندل & Dorema hyrcanum Kos-Pol & r \\
\hline ES-M-IT & Th & سوزن جويان & Scandix pecten-veneris $\mathrm{L}$. & $\Delta$ \\
\hline \multicolumn{5}{|c|}{ Asteraceae } \\
\hline IT & $\mathrm{Ch}$ & درمنه كوهى & Artemisia aucheri Boiss. & 4 \\
\hline ES-IT & $\mathrm{He}$ & 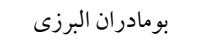 & Achillea millefolium $\mathrm{L}$. & $\checkmark$ \\
\hline IT & Th & كاجيره & Carthamus oxyacantha M.B. & $\wedge$ \\
\hline Cosm & $\mathrm{C}$ & كنگخر وحشى & Cirsium arvense (L.) Scop. var. arvens & 9 \\
\hline IT & $\mathrm{Ch}$ & كل گندم بوتهاى & Centaurea virgata Lam. & 1. \\
\hline IT & $\mathrm{He}$ & - & Cousinia lachnosphaera Bunge & 11 \\
\hline IT & $\mathrm{He}$ & شكر تيغال، تيهال & Echinops cephalotes DC. & ir \\
\hline IT & $\mathrm{He}$ & كنگر خوراكى & Gundelia tournefortii $\mathrm{L}$. & ir \\
\hline IT & Th & كاهوى نو كى دراز & Lactuca glauciifolia Boiss. & if \\
\hline \multicolumn{5}{|c|}{ Boraginaceae } \\
\hline ES-IT-M & Th & آنتاب برست & Heliotropium europaeum $\mathrm{L}$. & 10 \\
\hline \multicolumn{5}{|c|}{ Berberidaceae } \\
\hline ES-M- IT & $\mathrm{Ph}$ & 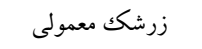 & Berberis vulgaris L. & 19 \\
\hline \multicolumn{5}{|c|}{ Brassicaceae } \\
\hline IT-M & Th & قدومهى بركى باريك & Alyssum linifolium Steph. ex Willd. & iv \\
\hline Cosm & Th & 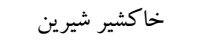 & Descurainia sophia (L.) Webb \& Berth & 11 \\
\hline \multicolumn{5}{|c|}{ Capparaceae } \\
\hline IT & Th & 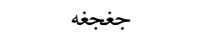 & Cleome khorassanica Bge. \& Bein. ex Boiss. & 19 \\
\hline \multicolumn{5}{|c|}{ Caryophyllaceae } \\
\hline IT & $\mathrm{Ch}$ & 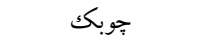 & Acantophyllum glandulosum Bunge ex Boiss. & r. \\
\hline IT & $\mathrm{Ch}$ & ميخك شرقى & $\begin{array}{l}\text { Dianthus orientalis Adams subsp. Stenocalyx (Boiss.) } \\
\text { Rech.f. }\end{array}$ & r \\
\hline
\end{tabular}




\begin{tabular}{|c|c|c|c|c|}
\hline IT & $\mathrm{Th}$ & گَج دوست & Gypsophila bicolor (Freyn \& Sint.) Grossh. & ry \\
\hline IT & $\mathrm{Th}$ & - & Minuartia meyeri (Boiss.) Bornm. & r \\
\hline IT-M & $\mathrm{Th}$ & 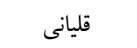 & Silene conoidea $\mathrm{L}$. & rF \\
\hline \multicolumn{5}{|c|}{ Chenopodiaceae } \\
\hline IT-M & $\mathrm{Th}$ & درمنه تركى & Chenopodium botrys $\mathrm{L}$. & ro \\
\hline \multicolumn{5}{|c|}{ Dipsacaceae } \\
\hline IT & $\mathrm{Th}$ & 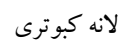 & Scabiosa persica Boiss. & rq \\
\hline \multicolumn{5}{|c|}{ Ephedraceae } \\
\hline ES-IT & $\mathrm{Ch}$ & ارمكك كبير & Ephedra major Host & rV \\
\hline \multicolumn{5}{|c|}{ Euphorbiaceae } \\
\hline IT & $\mathrm{He}$ & فرفيون & Euphorbia szovitsii Fisch. \& C.A.Mey. & rA \\
\hline ES-IT & $\mathrm{Th}$ & فرفيون & Euphorbia helioscopia L. & rq \\
\hline \multicolumn{5}{|c|}{ Fabaceae } \\
\hline IT-Ss & $\mathrm{Th}$ & كون & Astragalus commixtus Bunge & r. \\
\hline IT & $\mathrm{He}$ & كون & Astragalus schahrudensis Bunge & r \\
\hline IT & $\mathrm{Ch}$ & 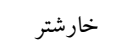 & Alhagi persarum Boiss. \& Buhse & rr \\
\hline IT & Th & شنبليه وحشى & Trigonella monantha C.A.Mey. & $\pi$ \\
\hline \multicolumn{5}{|c|}{ Juncaceae } \\
\hline Cosm & $\mathrm{C}$ & سازو-سمار & Juncus articulates L. & re \\
\hline \multicolumn{5}{|c|}{ Lamiaceae } \\
\hline IT-M & Th & - & Acinos graveolens (M.B.) Link. & ro \\
\hline IT & $\mathrm{He}$ & 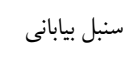 & Eremostachys macrophylla Montbr \& Auch. & rq \\
\hline IT & $\mathrm{Ch}$ & 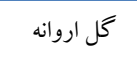 & Hymenocrater bituminosus Fisch. \& C.A. Mey. & rv \\
\hline IT & Th & بالنكو & Lallemantia royleana (Benth.in wall.) Benth. & r \\
\hline IT-M & $\mathrm{Ch}$ & فراسيون & Marrubium vulgare $\mathrm{L}$. & rq \\
\hline Cosm & $\mathrm{C}$ & يونه & Mentha longifolia (L.) Hudson & r. \\
\hline
\end{tabular}




\begin{tabular}{|c|c|c|c|c|}
\hline IT & $\mathrm{Th}$ & يونه ساى بر گه دار & Nepeta bracteata Benth. & \&l \\
\hline IT & $\mathrm{He}$ & - & Nepeta persica Boiss. & Gr \\
\hline IT & $\mathrm{He}$ & ن ت ن توروزك & Salvia leriifolia Benth. & kr \\
\hline IT-M & $\mathrm{He}$ & كليوره & Teucrium polium L. & kq \\
\hline IT & $\mathrm{Th}$ & 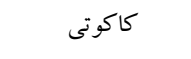 & Ziziphora tenuior L. & ro \\
\hline \multicolumn{5}{|c|}{ Liliaceae } \\
\hline IT & $\mathrm{C}$ & 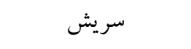 & Eremurus olgae Regel & k9 \\
\hline \multicolumn{5}{|c|}{ Oleaceae } \\
\hline IT & $\mathrm{Ph}$ & زبان كنجشك & Fraxinus rotundifolia Mill. & FV \\
\hline \multicolumn{5}{|c|}{ Platanaceae } \\
\hline ES-IT & $\mathrm{Ph}$ & جنار شرقى & Platanus orientalis L. & in \\
\hline \multicolumn{5}{|c|}{ Plumbaginaceae } \\
\hline IT & $\mathrm{Ch}$ & كلاه مير حسن & Acantholimon spinicalyx Koeie \& Rech.f. & kq \\
\hline \multicolumn{5}{|c|}{ Poaceae } \\
\hline Cosm & $\mathrm{Th}$ & جارو علفى & Bromus tectorum $\mathrm{L}$. & $\Delta$ \\
\hline IT & $\mathrm{He}$ & 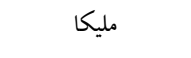 & Melica persica Kunth. & $\Delta 1$ \\
\hline ES-M-IT & $\mathrm{He}$ & 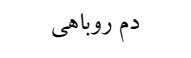 & Phleum phleoides (L.) Karsten & $\Delta r$ \\
\hline IT-M & $\mathrm{He}$ & 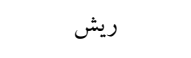 & Stipa barbata Desf. & $\Delta r$ \\
\hline \multicolumn{5}{|c|}{ Polygonaceae } \\
\hline IT & $\mathrm{He}$ & هفت بند عقربكى & Polygonum paronychioides C.A.Mey. ex Hohen. & $\Delta F$ \\
\hline IT & $\mathrm{Ph}$ & 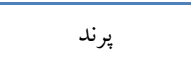 & Pteropyrum aucheri Jaub. \& Spach & $\Delta \Delta$ \\
\hline IT & $\mathrm{He}$ & ت ترشك ايرانى & Rumex chalepensis Mill. & $\Delta 9$ \\
\hline \multicolumn{5}{|c|}{ Ranunculaceae } \\
\hline M-IT-ES & $\mathrm{Th}$ & 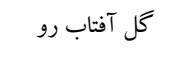 & Ceratocephalus falcetea (L.) Pers. & $\Delta V$ \\
\hline IT & $\mathrm{Th}$ & زبان در قفاى شرقى & Consolida orientalis (J. Gay) R. Schrod. & $\Delta \wedge$ \\
\hline \multicolumn{5}{|c|}{ Rosaceae } \\
\hline IT-M & $\mathrm{Ph}$ & تمشك درختى & Rubus sanctus Schreb & $\Delta 9$ \\
\hline
\end{tabular}




\begin{tabular}{|c|c|c|c|c|}
\hline IT & $\mathrm{Ch}$ & رز ايرانى & Rosa persica Mielx ex Juss. & 4. \\
\hline IT & $\mathrm{Ph}$ & ر ت رفيد & Rosa beggeriana Schrenk & 91 \\
\hline \multicolumn{5}{|c|}{ Rubiaceae } \\
\hline IT & $\mathrm{Ch}$ & 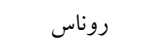 & Rubia florida Boiss. & ar \\
\hline IT-M-ES & Th & 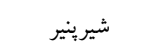 & Galium aparine $\mathrm{L}$. & $a r$ \\
\hline \multicolumn{5}{|c|}{ Salicaceae } \\
\hline IT & $\mathrm{Ph}$ & بيد سفيد & Salix alba $\mathrm{L}$. & aq \\
\hline IT & $\mathrm{Ph}$ & 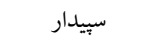 & Populus alba $\mathrm{L}$. & 90 \\
\hline \multicolumn{5}{|c|}{ Scrophulariaceae } \\
\hline IT-M-ES & Th & سيزاب عشقهاى & Veronica hederifolia $\mathrm{L}$. & 99 \\
\hline \multicolumn{5}{|c|}{ Solanaceae } \\
\hline Cosm & Th & تاجريزى سياه & Solanum nigrum $\mathrm{L}$. & $9 \mathrm{~V}$ \\
\hline \multicolumn{5}{|c|}{ Valerianaceae } \\
\hline IT & $\mathrm{He}$ & سنبل الطيب & Valeriana sisymbriifolia Vahl. & 91 \\
\hline \multicolumn{5}{|c|}{ Zygophyllaceae } \\
\hline ES-M-IT & $\mathrm{He}$ & 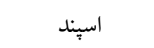 & Peganum harmala $\mathrm{L}$. & 99 \\
\hline
\end{tabular}

* شكلزيستى: Th= تروفيت، Ch= كامفيت، He= همى كرييتوفيت، Che= كرييتوفيت، Ph= فانروفيت

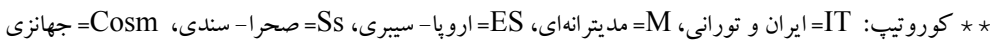

\section{منابع / References}

$$
\begin{aligned}
& \text { حـوزه آبخيز تير گَان (اسـتان خراسـان). - - نشـرية علوم دانشـكاه } \\
& \text { تربيت معلم 1 ن:19-1. } \\
& \text { بتولى، ح. بریr. - تنوع زيستى و غناى گونهاى عناصر گياهى }
\end{aligned}
$$

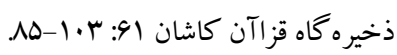

اسدى، م.، معصومى، ع.1.، خاتمساز، م. و مظفريان، و.1.

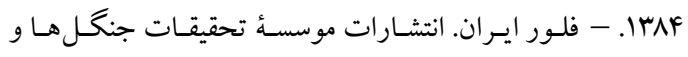
IrAV 
Amiri, M.S. and Jabbarzadeh, P. 2010. Floristic study of Zangelanlo watershed (Khorassan, Iran). - Taxonomy and Biosystematics 2:1-16.

Archibold, O.W. 1995. - Ecology of World Vegetation. Chapman and Hall Inc., London.

Ghahreman, A. 2004. - Cormophytes of Iran (Plant systematics. Iran University Press, 736p, Tehran.

Ghahreman, A. 1978-2006. - Flora of Iran / Flore de l' Iran en couleurs naturalles. Tehran: la Societe Nationale Pour la Conservation des Ressources Naturelles et de 1 Enviromnent Humain.

Hutchinson, G.E. 1975. - A Treatise on Limnology, Limnological Botany. John Wiley \& Sons Inc., 645 p, New York.

Rechinger, KH. Since 1963. - Flora Iranica. Graz: Akademische Druck-u Verlagsanstalt.

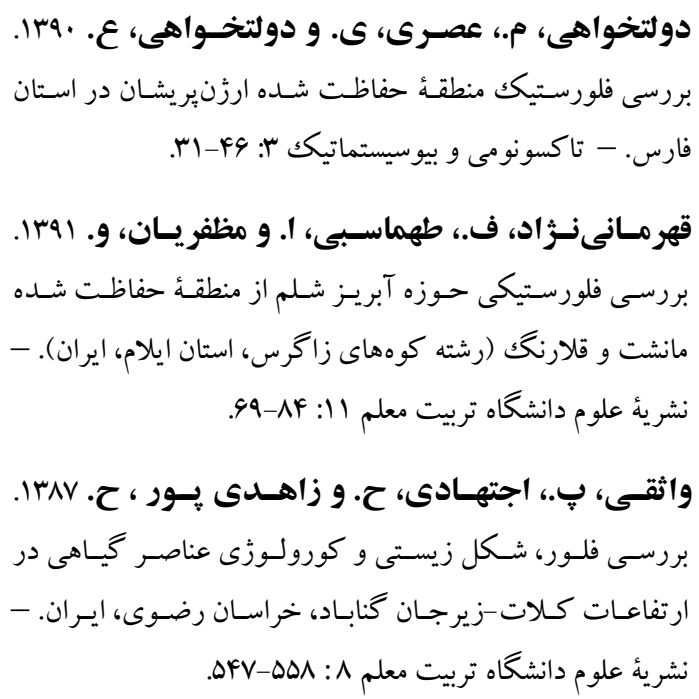

